\title{
Effect of increasing doses of long chain $n-3$ PUFA on heart rate, interbeat interval and heart rate variability in the MARINA study: a randomised controlled trial
}

\author{
W. L. Hall ${ }^{1}$, Z. Maniou ${ }^{1}$, F. Lewis ${ }^{1}$, P. T. Seed ${ }^{2}$, P. J. Chowienczyk ${ }^{3}$ and T. A. B. Sanders ${ }^{1}$ \\ ${ }^{1}$ School of Medicine, King's College London, Diabetes and Nutritional Sciences Division, Franklin-Wilkins Building, \\ 150 Stamford Street, London SE1 9NH, UK, ${ }^{2}$ Division of Women's Health, St Thomas' Hospital, London SE1 7EH, UK and \\ ${ }^{3}$ Cardiovascular Division, St Thomas' Hospital, London SE1 7EH, UK
}

Heart rate variability (HRV) describes measures of cardiac electrophysiology that can be recorded over $24 \mathrm{~h}$ to ascertain mean indices of cardiac responses to autonomic regulation. Lower HRV is associated with an increased risk of sudden cardiac death ${ }^{(1)}$. Observational data suggest that fish consumption might be associated with vagally-mediated HRV parameters measured in a cohort of older adults ${ }^{(2)}$. Furthermore, meta-analysis of fish oil trials concluded that $\geq 12$ weeks consumption reduced heart rate (HR) by 2.5 beats per min (bpm), with little evidence of a dose-response effect ${ }^{(3)}$.

The MARINA intervention trial (ISRCTN66664610) investigated whether low doses of long chain $n-3$ PUFA ( $n-3$ LCP), is equal to consuming one, two or four portions of oily fish per week, would lower HR and improved indices of HRV in healthy men and women (45-70 years). A parallel-design randomised controlled trial compared three levels $(0.45,0.9$ or $1.8 \mathrm{~g} / \mathrm{d})$ of $n-3 \mathrm{LCP}$ (EPA to DHA ratio 1.5) v. placebo (olive oil) taken for 12 months. Participants wore an Actiheart monitor (Cambridge Neurotechnology Ltd, Cambridge, UK) that measured $24 \mathrm{~h} \mathrm{HR}$, interbeat intervals (IBI) and triangular index (Ti), a time-domain geometric parameter of overall $\mathrm{HRV}^{(1)}$, at baseline, 6 and 12 months. Randomisation was carried out for 367 participants (142 men, 225 women; mean age 55 years (SD 7); mean BMI 26 (SD 4)). Of these, 312 completed the study and $24 \mathrm{~h}$ HR, IBI and HRV data were complete for 301 participants. Data were analysed using ANOVA adjusting for baseline levels, age, gender, BMI and ethnicity using Stata 11 software (StataCorp LP, College Station, TX 77845, USA). The mean value on treatment (6 and 12 months) was used in the analysis. Data are geometric means (GM) with $95 \%$ CI.

There was a slight trend towards a reduced HR at the highest dose (equivalent to four portions of oily fish per week) but the overall dose effect was not statistically significant. There was no dose-dependent treatment effect on HRV.

\begin{tabular}{|c|c|c|c|c|c|c|c|c|c|}
\hline & \multicolumn{2}{|c|}{ Placebo ( $n$ 67) } & \multicolumn{2}{|c|}{$0.45 \mathrm{~g} / \mathrm{d}(n 80)$} & \multicolumn{2}{|c|}{$0.9 \mathrm{~g} / \mathrm{d}(n 77)$} & \multicolumn{2}{|c|}{$1.8 \mathrm{~g} / \mathrm{d}(n 77)$} & \multirow[b]{2}{*}{$P$ value } \\
\hline & GM & $95 \% \mathrm{CI}$ & GM & $95 \% \mathrm{CI}$ & GM & $95 \% \mathrm{CI}$ & GM & $95 \% \mathrm{CI}$ & \\
\hline \multicolumn{10}{|l|}{$H R(b p m)$} \\
\hline Baseline & 72 & $69-74$ & 70 & $68-73$ & 71 & $68-74$ & 72 & $69-74$ & 0.06 \\
\hline 6 months & 73 & $71-75$ & 71 & $70-73$ & 71 & $69-74$ & 71 & $69-73$ & \\
\hline 12 months & 74 & $72-77$ & 72 & $70-74$ & 73 & $71-75$ & 71 & $69-73$ & \\
\hline \multicolumn{10}{|l|}{$I B I(m s)$} \\
\hline Baseline & 873 & $845-901$ & 885 & $856-916$ & 876 & 844-909 & 865 & $835-896$ & 0.08 \\
\hline 6 months & 860 & $835-885$ & 867 & $843-892$ & 864 & $837-892$ & 880 & $850-912$ & \\
\hline 12 months & 841 & $812-871$ & 866 & $843-889$ & 853 & $830-877$ & 878 & $853-903$ & \\
\hline \multicolumn{10}{|l|}{$H R V T i$} \\
\hline Baseline & 35 & $32-37$ & 37 & $35-40$ & 35 & $33-38$ & 38 & $35-41$ & 0.78 \\
\hline 6 months & 34 & $32-37$ & 36 & $34-38$ & 36 & $34-38$ & 35 & $32-38$ & \\
\hline 12 months & 34 & $31-36$ & 36 & $34-39$ & 35 & $33-37$ & 37 & $34-39$ & \\
\hline
\end{tabular}

In conclusion, intake of $n-3$ LCP at levels currently recommended in the UK has no effect on HR or HRV in healthy men and women, but there is some indication that there might be a slight HR-lowering effect at higher intakes.

Funding for this work was provided by the Food Standards Agency and the Department of Health, England (Project code N02041).

1. Task Force of the European Society of Cardiology and The North American Society of Pacing and Electrophysiology (1996) Eur Heart J 17, 354-381.

2. Mozaffarian D, Stein PK, Prineas RJ et al. (2008) Circulation 117, 1130-1137.

3. Mozaffarian D, Geelen A, Brouwer IA et al. (2005) Circulation 112, 1945-1952. 